\title{
Estudo da ação antimicrobiana conjunta de extratos aquosos de Tansagem (Plantago major I., Plantaginaceae) e Romã (Punica granatum I., Punicaceae) e interferência dos mesmos na ação da amoxicilina in vitro
}

TELES, D.G. ${ }^{1}$; COSTA, M.M. ${ }^{2}$

${ }^{1}$ Faculdade de Saúde Ibituruna - FASI. Avenida Nice, 99 - Bairro Ibituruna - Montes Claros MG - CEP 39401303 - email: diego.d.gt@hotmail.com; ${ }^{2}$ Faculdade de Saúde Ibituruna - FASI. Avenida Nice, 99 - Bairro Ibituruna - Montes Claros MG - CEP 39401-303

\begin{abstract}
RESUMO: O uso de plantas medicinais no tratamento de doenças (fitoterapia) é uma prática de diversos povos, sendo realizada desde a Antiguidade. Diversos estudos são realizados para determinar a eficácia dessas plantas, sendo desconhecida a existência de interações e interferências na combinação das mesmas, quer seja benéfica, quer cause algum dano para o organismo. A fim de descobrir a existência dessas interações ou a interferência na ação do antibiótico amoxicilina testou-se Punica granatum e Plantago major contra as bactérias Staphylococcus aureus e Escherichia coli. A matéria prima foi obtida nas regiões de Montes Claros e Curvelo e seus extratos aquosos foi obtido através da decocção. A Concentração Inibitória Mínima (CIM) dos extratos foi determinada pela técnica de microdiluição em caldo. Para o teste de interferência realizou-se o teste de disco-difusão. No teste de microdiluição em caldo, Punica granatum apresentou CIM de $6,25 \%$ contra o S. aureus e de $25 \%$ contra E. coli. O extrato de Plantago major não apresentou atividade contra as bactérias. O teste de discodifusão confirmou a existência de interações, sendo apenas quatro resultados significativos (Amoxicilina + Plantago major Pura (PgP), Amoxicilina + Plantago major Diluição $1\left(P g \mathrm{D}_{1}\right)$ e Amoxicilia + Plantago major Diluição $2\left(\mathrm{PgD}_{2}\right)$ contra E. coli e Amoxicilina + PgP contra $S$. aureus). Conclui-se que existe interação dos extratos entre si e dos extratos com a amoxicilina, o que também pode acontecer com outros antibióticos e gerar riscos para a população. Portanto é indispensável à realização de testes que complementem essa pesquisa oferecendo mais informação à população para segurança na utilização de plantas medicinais.

informações à população assegurando sua segurança na utilização de plantas medicinais.
\end{abstract}

Palavras chave: Fitoterapia. Sinergismo. Plantago major L.. Punica granatum L..

ABSTRACT: Study of the joint antimicrobial action of aqueous extracts of broadleaf plantain (Plantago major I., Plantaginaceae) and Pomegranate (Punica granatum I., Punicaceae) and their interference in the in vitro activity of amoxicillin. The use of medicinal plants in treating diseases (herbal medicine) is a practice of many peoples, being done since ancient times. Several studies are conducted to determine the effectiveness of these plants, but the existence of interactions and interference with their combined use, whether beneficial or detrimental to the body, are unknown. In order to discover the existence of these interactions or interferences in the activity of the antibiotic amoxicillin, we tested in this research Punica granatum and Plantago major against Staphylococcus aureus and Escherichia coli. The raw material was obtained in the regions of Montes Claros and Curvelo, and their aqueous extracts were obtained from decoction. The minimum inhibitory concentration (MIC) of the extracts was determined by the broth microdilution technique. For interference, we performed the disk diffusion test. In the broth microdilution test, Punica granatum had MICs of $6.25 \%$ against S.aureus and $25 \%$ against E. coli. The Plantago major extract showed no activity against the bacteria. The disk diffusion test confirmed the existence of interactions and only four significant results (amoxicillin + pure Punica granatum $(P g P)$, amoxicillin + Punica granatum dilution 1 (PgD1) and amoxicillin + Punica granatum dilution 2 (PgD2) against $E$. coli and amoxicillin + $P g P$ against $S$. aureus). We conclude, as a result, that there really is interaction between the extracts themselves and between the extracts and amoxicillin, which can also occur with other 
antibiotics and cause some risk to the population. Therefore, it is essential to carry out tests to complement this research, providing more information to the public and ensuring the safety in the use of medicinal plants.

Keywords: Herbal Medicine. Synergism. Plantago major L. Punica granatum L.

\section{INTRODUÇÃO}

O uso de plantas medicinais no tratamento de doenças vem aumentando a cada dia em todo o mundo. No Brasil não é diferente, tanto nos grandes centros comerciais quanto no interior, o comércio e a utilização de plantas medicinais são atividades muito difundidas, às quais são atribuídas diversas causas, sejam de ordem médica, social, cultural, econômica ou filosófica (PERON et al., 2008). Segundo Veiga Jr. et al. (2005), a Organização Mundial de Saúde (OMS) define planta medicinal como sendo qualquer vegetal que possui substâncias que podem ser utilizadas com fins terapêuticos ou que sejam utilizadas na produção de fármacos semi-sintéticos. Lorenzi e Matos (2002) afirmam que toda planta medicinal é medicamento apenas quando tem seu princípio ativo identificado e é utilizada de maneira correta.

Para Maciel et al (2002), a utilização de fitoterápicos no tratamento e cura de doenças é tão antigo quanto a humanidade, sendo que o primeiro manuscrito conhecido a respeito de seus usos data de 1500 a.C. (TESKE; TRENTINI, 1994 apud LIMA-JÚNIOR et al., 2006). Taufner, Ferraço e Ribeiro (2006) afirmam que os fitoterápicos são utilizados pela população como alternativa para cura de doenças e como forma alternativa ao tratamento com medicamentos alopáticos. Precauções contra o mau uso de plantas medicinais devem ser levadas em consideração, e a obediência às dosagens prescritas e o cuidado na identificação precisa do material utilizado podem evitar uma série de acidentes (LORENZI; MATOS, 2002).

Punica granatum (romã) e Plantago major (tansagem), são constantemente utilizadas pela população no tratamento de sintomas e doenças. Punica granatum L. é uma planta da família Punicaceae, conhecida popularmente como romanzeira, romeira e granado. É amplamente encontrada por todo Brasil sendo originária da Ásia (BRAGA, 1961 apud OLIVEIRA et al., 2010). Segundo Menezes et al. (2008), essa planta é utilizada como adstringente, hemostática, antidiabética, antihelmíntica, antidiarréica, antisséptico e antiviral. Naqvi, Khan e Vohora (1991), citados por Pereira et al (2006), avaliaram a atividade antimicrobiana do extrato de Punica granatum sobre microrganismos Gram positivos e leveduras, confirmando a presença de princípios ativos antimicrobianos na casca do fruto. O perfil químico de seus extratos demonstrou que entre os seus principais fitoconstituintes estão os flavonóides (apigenina e narigenina), antocianinas, taninos (ácidos gálico e elágico), alcalóides, ácido ascórbico, ácidos graxos conjugados (ácido púnico) e o ácido ursólico (LANSKY; NEWMANN, 2007).

O extrato da casca da romã também é rico em polifenóis, os quais têm apresentado um forte efeito antisséptico e também atividade antibacteriana contra gram-negativas e grampositivas (Negi, P. S. Jayaprakasha, G. K, 2003). Muitos estudos demonstram a eficácia biológica da Punica granatum, tal como seu potencial para inibição do crescimento de bactérias grampositivas, especialmente do Staphylococcus aureus (PRASHANTH, D., ASHA, M.K., AMIT, 2001).

Plantago major é uma planta herbácea que cresce em clima temperado ou subtropical e é utilizada no tratamento de inflamações de boca e garganta, infecções intestinais, e como agente antibacteriano (FREITAS et al., 2002). Pertence à família das Plantaginaceaes, sendo de porte pequeno, em roseta ereta, podendo atingir cerca de 20 a $30 \mathrm{~cm}$ de altura e de ciclobienal ou perene. (CORDEIRO, 2005). Segundo Samuelsen (2000), $P$. major contém compostos biologicamente ativos, como polissacarídeos, lipídios, derivados do ácido cafeico, flavonóides, glicosídeos iridóides e terpenóides. O chá das folhas é popularmente difundido para o tratamento de amigdalite, estomatite e faringite, e, externamente, indicado para tratar úlceras e feridas, ou,sob forma de emplastro, como cicatrizante (Bieski, 2005). Em testes, a Plantago major $\mathrm{L}$, apresentou eficácia semelhante à da clorexidina no controle de sangramento e recuperação tecidual de gengivas de pacientes com periodontite (CATÃO, M.H.C. V. et al, 2012)

Existem vários estudos à cerca da eficácia de diversas plantas utilizadas pela população, sendo desconhecida a existência de interações e interferências benéficas ou maléficas ao organismo no uso combinado dessas plantas. As pesquisas realizadas para a avaliação do uso seguro de plantas medicinais e fitoterápicos no Brasil ainda são incipientes, assim como o controle da comercialização pelos órgãos oficiais em feiras livres, mercados públicos ou lojas de produtos naturais (VEIGA JR et al.,2005). Nosso objetivo nesse estudo foi investigar a existência de interações na utilização conjunta de extratos aquosos de $P$. granatum e $P$. major e a interferência dos mesmos na ação da Amoxicilina in vitro, bem comoidentificar

Rev. Bras. PI. Med., Campinas, v.16, n.2, supl. I, p.323-328, 2014. 
a Concentração Inibitória Mínima dos extratos frente às cepas padrão de Staphylococcus aureus e Escherichia coli e fornecer subsídios quanto para a melhor utilização dessas plantas visando minimizar riscos para a população. Segundo Nascimento et al., (2000) as plantas medicinais ou seus subprodutos podem inibir, intensificar ou mesmo não interferir no efeito terapêutico dos medicamentos convencionais, e essa utilização associada pode colocar o paciente em risco. Assim, é de extrema importância investigar a existência de interações na utilização conjunta de plantas no tratamento de infecções e de interações entre plantas e antibióticos industrializados devido aos riscos que essas interações podem oferecer, afinal, a fitoterapia apresenta grande potencial para tratamento de enfermidades, cabendo aos profissionais da saúde orientar a população de forma segura na utilização das plantas para tratar doenças.

\section{MATERIAIS E MÉTODO}

\section{Tipo de pesquisa} qualitativa.

Esta foi uma pesquisa exploratória e

\section{Matéria prima}

A matéria prima (cascas secas de Punica granatum e folhas secas de Plantago major) foi obtida de origem diversa, no Mercado Municipal de Montes Claros e da região de Curvelo. Todo o material vegetal foi submetido à identificação botânica pela professora Suerlani Aparecida Moreira e as exsicatas foram depositadas no acervo do Laboratório de Botânica da Faculdade de Saúde Ibituruna.

\section{Extratos}

Os extratos foram obtidos pelo método de decocção. Para o extrato de $P$. granatum L., $25 \mathrm{~g}$ de cascas de seu fruto foram fervidos em $50 \mathrm{~mL}$ água destilada estéril durante um minuto. $O$ extrato foi filtrado em papel filtro e foi obtido extrato aquoso na proporção de $1 / 2(50 \%)$. O extrato de $P$ major L. obtido teve proporção 1/1 (100\%). Para sua obtenção foram pesadas $50 \mathrm{~g}$ de folha secas, às quais foram adicionadas $50 \mathrm{~mL}$ de água destilada estéril, sendo submetidas a fervura por um minuto. Este extrato também foi filtrado em papel filtro.

\section{Bactérias}

Foram utilizadas cepas padrão de Staphylococcus aureus (ATCC 6835) e Escherichia coli (ATCC 25922), obtidas de culturas com 24 horas, cultivadas em ágar Muller Hinton (HIMEDIA, Índia).

\section{Concentração Inibitória Mínima (CIM)}

A Concentração Inibitória Mínima (CIM) dos extratos aquosos foi determinada pela técnica de microdiluição em caldo, de acordo com o preconizado pelo CLSI (Clinical Laboratory Standards Institute), utilizando-se microplacas de diluição com 96 poços. Cada poço recebeu $100 \mu \mathrm{L}$ de caldo Muller Hinton (HIMEDIA, Índia), $50 \mu \mathrm{L}$ de um dos extratos, sendo uma concentração diferente para cada poço (diluição em série) e $50 \mu \mathrm{L}$ de uma das suspensões bacterianas padronizadas com a escala de Mc Farland 0,5. As microplacas foram incubadas por 24 horas a $35 \pm 2^{\circ} \mathrm{C}$. Após a incubação foram acrescentados em cada poço $20 \mu \mathrm{L}$ de solução de resazurina $0,01 \%$ previamente preparada. As placas foram novamente incubadas e o resultado foi observado nos tempos 60, 120, 180 e 240 minutos. Foram utilizados como controles os antibióticos gentamicina e oxacilina para E. coli e $S$. aureus, respectivamente.

\section{Teste de disco-difusão}

Para investigar a existência de interações foi realizado o teste de disco-difusão descrito por Kirby-Bauer. Foram utilizadas neste teste as proporções dos extratos que apresentaram atividade antimicrobiana no teste de CIM. Foram realizados antibiogramas para controle e teste, onde discos de papel de $6 \mathrm{~mm}$ foram impregnados com $20 \mu \mathrm{L}$ de extrato aquoso de cada planta para controle, enquanto outros discos, impregnados com a mistura dos extratos ( $20 \mu \mathrm{L}$ cada) em diferentes proporções, compuseram o teste de interação dos extratos entre si. Foram utilizados discos comercias do antibiótico amoxicilina, para antibiograma, no teste de interação do antibiótico com os extratos, sendo os mesmos impregnados com $20 \mu \mathrm{L}$ dos extratos em diferentes concentrações. As bactérias foram inoculadas em ágar Muller Hinton a partir de suspensões bacterianas padronizadas com escala de Mc Farland 0,5; por meio da técnica de estria em véu. Após serem colocados os discos sobre o inóculo, as placas foram invertidas e incubadas em estufa bacteriológica a $35 \pm 2^{\circ} \mathrm{C}$ por 24 horas. Posteriormente, as placas foram analisadas individualmente para a leitura, observando a formação e o tamanho dos halos, fazendo a comparação entre os testes e os controles. Considerou-se que houve interação quando a diferença entre o halo do controle e o halo do teste foi igual ou maior do que $2 \mathrm{~mm}$, conforme técnica descrita por Canton e Becker (2010). Todos os testes foram realizados em triplicata.

\section{RESULTADOS E DISCUSSÃO}

\section{Teste de microdiluição em caldo}

No teste de microdiluição em caldo foram

Rev. Bras. PI. Med., Campinas, v.16, n.2, supl. I, p.323-328, 2014. 
encontrados resultados característicos de atividade antimicrobiana nas quatro primeiras diluições $(50 \%$, $25 \%, 12,5 \%$ e $6,25 \%$ ) do extrato de Punica granatum sendo a CIM (Concentração Inibitória Mínima), portanto, de 6,25\% para o Staphylococcus aureus. Catão et al., (2006), observou que a CIM do extrato etanólico de $P$. granatum foi de $10 \%$, contra cepas de $S$. aureus de origem ambulatorial. Essa diferença pode ocorrer devido às técnicas de extração não terem a mesma eficácia ou também porque as cepas de origem ambulatorial tem maior possibilidade de sofrer mutação e adquirir resistência em comparação às cepas padrão ATCC, o que pode ocorrer também com os outros extratos. Contra a Escherichia coli a Punica granatum apresentou atividade nas duas primeiras diluições (50\% e $25 \%$ ), sendo de $25 \%$ a CIM contra essa bactéria. Já para o extrato de Plantago major não se observou resultado colorimétrico satisfatório para ambas as bactérias em nenhuma diluição, o que pode ser interpretado como ausência de atividade antibacteriana, concentração ineficaz do extrato ou como a existência de interferência de alguma substância do extrato. Eloff (1998) citado por Ostrosky et al. (2008) utilizou a técnica de diluição em microplacas para verificar a atividade antimicrobiana em extratos vegetais e observou inconvenientes na técnica, como células de alguns microrganismos que se aderiam à base do poço e outras que ficavam em suspensão. Alguns compostos dos extratos precipitavam e a coloração verde da clorofila em concentração muito alta interferia na análise.

\section{Teste de disco-difusão}

Os resultados para o teste de disco de difusão para Escherichia coli e Staphylococcus aureus estão apresentados na Tabela 1 e Tabela 2 , respectivamente. $O$ extrato de $P$. major não apresentou atividade contra as bactérias nas diferentes concentrações testadas de forma isolada. O extrato de $P$. granatum apresentou indícios de atividade antimicrobiana contra a $E$. coli nas três primeiras concentrações 50,0 \%, 25,0 \% e 12,5 $\%$, pois, observou-se crescimento bacteriano menos intenso e com colônias bem pequenas nas proximidades dos discos, o que sugere que em concentrações mais elevadas do extrato exista a atividade antimicrobiana contra a E. coli. Nos discos com diferentes combinações dos extratos observouse que para a $E$. coli nenhuma das combinações das diferentes concentrações dos extratos foi eficiente e que aparentemente o extrato de $P$. major interferiu na ação do extrato de $P$. granatum, pois quando analisados os halos formados, percebeu-se que com a redução da concentração do extrato de $P$. major obteve-se halos maiores do que os formados ao redor dos discos com a combinação dos extratos puros. Em comparação com os extratos isolados a $P$. major aparentemente auxiliou a atividade da $P$. granatum, pois houve a formação de halos quando os extratos foram combinados e já para os extratos de forma isolada não, o que sugere que, de forma isolada, os extratos são ineficazes contra a $E$. coli e que possa existir alguma combinação de concentrações dos extratos que seja eficaz. Deve-se ressaltar, porém, que nenhuma das combinações dos extratos foi eficiente contra a E. coli, pois apesar de ocorrer a formação de halos, os mesmos não eram nítidos e apresentavam início de proliferação bacteriana em seus interiores. Zago et al. (2009), afirmam em seu estudo sobre sinergismo entre óleos essenciais e drogas antimicrobianas, que a espécie do microrganismo interfere com os resultados, o que foi verificado pela baixa frequência de sinergismo dos óleos e drogas contra linhagens de E. coli em comparação ao $S$. aureus. Nas combinações

TABELA 1. Resultado do teste de disco de difusão para E. coli

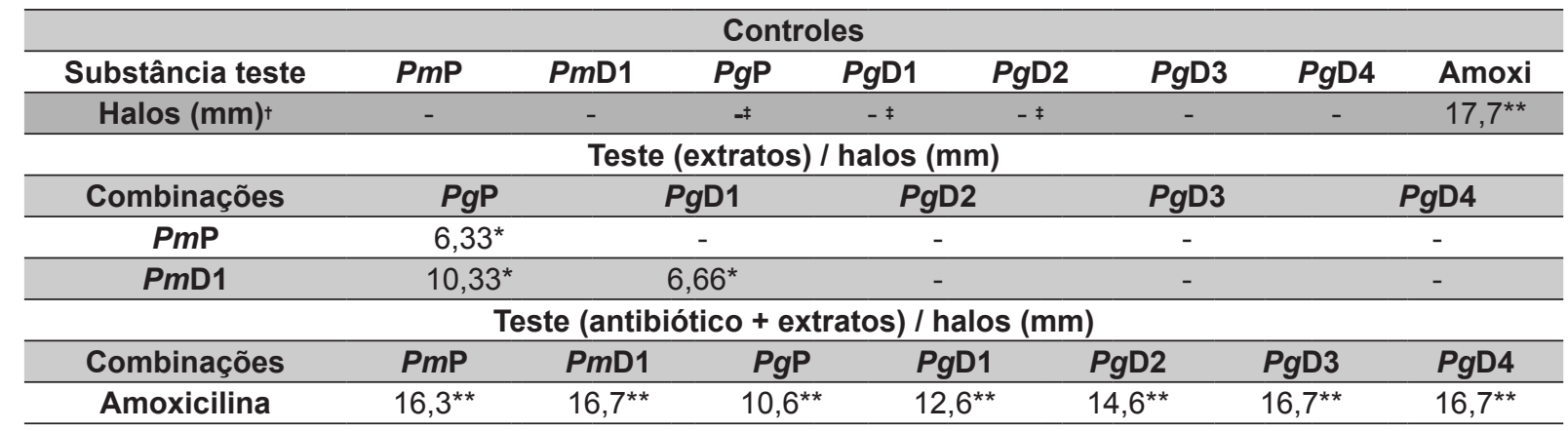

Legenda: PmP (Plantago major Pura), PgP (Punica granatum Pura), D1 (diluição 1), D2 (diluição 2), D3 (diluição 3), D4 (diluição 4) e Amoxi (Amoxicilina).

†Valores médios das três repetições realizadas para o teste.

‡ Houve crescimento bacteriano, mas, na proximidade dos discos esse crescimento foi menos intenso com colônias bem pequenas.

* Foi observado o início de proliferação bacteriana no interior dos halos formados.

** Halos nítidos.

Rev. Bras. PI. Med., Campinas, v.16, n.2, supl. I, p.323-328, 2014. 
TABELA 2. Resultado do teste de disco de difusão para S. aureus

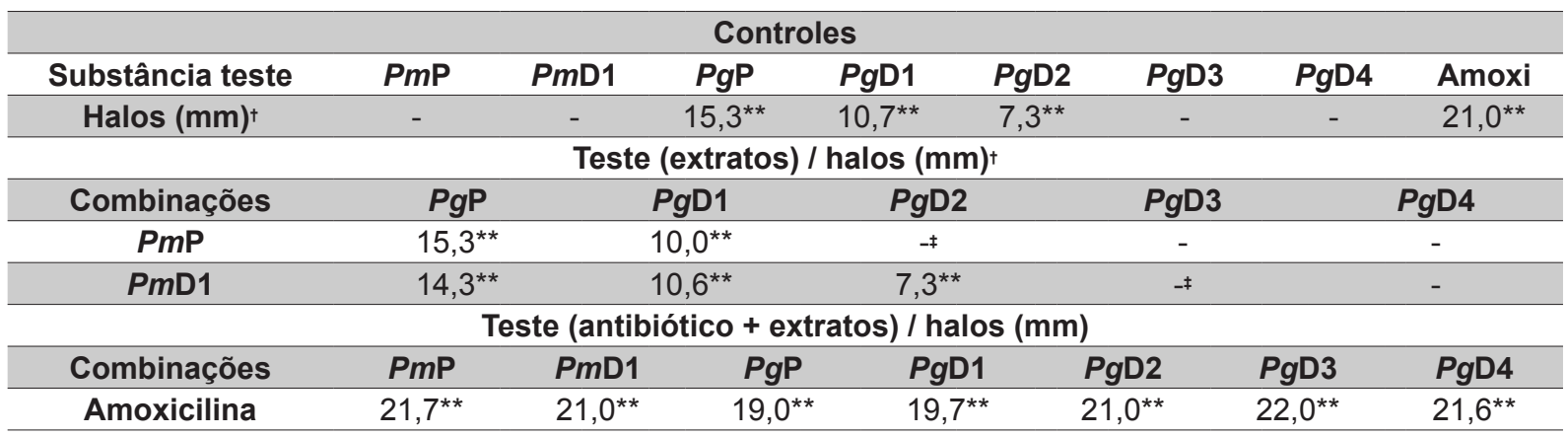

Legenda: PmP (Plantago major Pura), PgP (Punica granatum Pura), D1 (diluição 1), D2 (diluição 2), D3 (diluição 3), D4 (diluição 4) e Amoxi (Amoxicilina).

†Valores médios das três repetições realizadas para o teste.

¥ Houve crescimento bacteriano, mas, na proximidade dos discos esse crescimento foi menos intenso com colônias bem pequenas.

** Halos nítidos.

das diferentes concentrações dos extratos com o antibiótico amoxicilina, observou-se que contra a $E$. coli os extratos interferiram negativamente na ação da amoxicilina, pois, à medida que se aumentava a concentração dos extratos diminuía-se a ação do antibiótico, o que se tornou evidente com a diminuição do tamanho dos halos formados.

Contra o S. aureus observou-se que o extrato de $P$. major intensificou a ação do extrato de $P$. granatum, pois, quando analisados os halos formados, percebeu-se que estes aumentavam de tamanho quando aumentada a concentração de $P$. major, o que é evidenciado quando se compara os discos com a combinação dos extratos puros (halos com média de 15,3 mm), com os discos com o extrato puro da $P$. granatum e a primeira diluição do extrato de $P$. major (halos com média de 14,3 $\mathrm{mm}$ ). Já em comparação com os discos contendo apenas o extrato de $P$. granatum puro percebe-se que a média do tamanho dos halos formados é a mesma $(15,3 \mathrm{~mm})$, indicando que se aumentada a concentração de $P$. major na combinação, provavelmente haverá um aumento da atividade antibacteriana, com consequente aumento dos halos formados em comparação com a concentração do extrato de $P$. granatum utilizada nos testes. Contra o $S$. aureus, o extrato de $P$. major mostrou interação positiva com o antibiótico, visto que, o tamanho dos halos formados foi maior quando o antibiótico estava combinado com o extrato puro. Já o extrato de $P$. granatum parece interferir de duas formas distintas na ação do antibiótico, pois, quando mais concentrado, o extrato reduziu a atividade do antibiótico e já nas últimas concentrações, ou seja, quando o extrato estava mais diluído, ele intensificou a ação da amoxicilina, mostrando que em baixas concentrações a $P$. granatum pode auxiliar na ação da amoxicilina contra o $S$. aureus. Segundo Auricchio et al., (2003) citado por Alves et al (2008), quando se comparam estudos de atividade antimicrobiana de extratos de plantas medicinais, é notória a dificuldade de comparação entre os resultados, pois as variáveis vão dos aspectos climáticos que exercem influência na composição química, como o estágio de desenvolvimento do vegetal quando da sua coleta, parte da planta estudada, forma de preparar o material para estudo e, principalmente, os protocolos seguidos nos experimentos.

Sendo assim, nas concentrações e proporções testadas apenas quatro resultados foram considerados significativos (Amoxi $+P g P$, Amoxi + PgD1 e Amoxi + PgD2 contra E. coli e Amoxi + PgP contra S. aureus).Apenas nestas combinações a variação dos halos foi igual ou superior a $2 \mathrm{~mm}$ em comparação aos halos formados pelos respectivos controles. Este procedimento está de acordo com o exposto por Canton e Becker (2010) em seu trabalho sobre a interferência de extratos na ação de antibióticos usados na clínica, onde eles afirmam que há sinergismo quando a diferença entre os halos de inibição de crescimento microbiano dos testes, comparados aos controles, é $\geq$ a $2 \mathrm{~mm}$. Quando essa diferença é menor do que $2 \mathrm{~mm}$, considerase como efeito indiferente e quando os halos formados pelos testes é menor que os do controle há antagonismo entre os extratos, de acordo com testes estatísticos.

\section{CONCLUSÃO}

Diante dos resultados obtidos, concluiu-se que realmente existe interação dos extratos entre si e dos extratos com a amoxicilina, o que indica a possibilidade dos extratos de plantas medicinais também interagirem com outros antibióticos oferecendo riscos à saúde da população, podendo diminuir a eficácia dos tratamentos alopáticos. As 
plantas medicinais são amplamente utilizadas pela população e é indiscutível que elas representam uma importante alternativa para o tratamento e cura de doenças, mas, desde que sejam respeitadas e observadas suas características. Destacase, portanto, a necessidade de realização de testes que venham complementar essa pesquisa, oferecendo mais informações à população sobre os componentes, as interações, os riscos, e os benefícios que essas plantas podem oferecer.

\section{REFERÊNCIA}

ALVES et al. Estudo comparativo de técnicas de screening para avaliação da atividade antibacteriana de extratos brutos de espécies vegetais e de substâncias puras. Núcleo de Pesquisa em Ciências Exatas e Tecnológicas, Universidade de Franca, Av. Dr. Armando Salles Oliveira, 201, 14404-600 Franca - SP, Brasil. Química Nova, v. 31, n. 5, p. 1224-1229, 2008.

BIESKI, I.G.C. Plantas medicinais e aromáticas no sistema único de saúde da região sul de CuiabáMT. Disponível em http://www.esalq.usp.br/siesalq/pm/ isanete3.pdf. acesso em 07 de maio de 2013.

CANTON, M.; BECKER, S. O. Interferência de extratos da Accharis dracunculifolia DC., Asteraceae, sobre a atividade de antibióticos usados na clínica. Revista Brasileira de Farmacognosia. v. 20, n.3, p. 348-354, 2010.

CATÃO, M.H.C. V. et al. Estudos Clínicos com Plantas Medicinais no Tratamento de Afecções Bucais: Uma Revisão de Literatura. UNOPAR Cient Ciênc Biol Saúde 2012;14(4):279-85 .

CATÂO, R. M. R. et al. Atividade antimicrobiana "in vitro" do extrato etanólico de Punica granatum linn. (romã) sobre isolados ambulatoriais de Staphylococcus aureus. Revista Brasileira de Análises Clínicas, v. 38 n. 2, p. 111-114, 2006.

CORDEIRO, C. H. G. Atividade biológica de gel dentifrício e enxagüatório bucal contendo extratos vegetais. Araraquara, São Paulo, 2005. Disponível em : http://www.athena.biblioteca.unesp.br/exlibris/bd/ bfa/33004030078P6/2005/cordeiro_chg_me_arafcf.pdf . Acesso em 18 de jun., 2011.

FREITAS, A. G. et al. Atividade antiestafilocócica do Plantago major L. Revista Brasileira de Farmacognosia. v. 12, suppl. 1, p. 64-65, 2002.

LANSKY, E. P., NEWMANN, R. A.. Punica granatum (pomegranate) and its potential for prevention and treatment of inflammation and cancer. $J$ Ethnopharmacol. n. 109, p. 177-206, 2007.

LIMA-JÚNIOR, J. F. et al. A Fitoterapia na Saúde Pública em Natal/RN: visão do odontólogo. Saúde em Revista, Piracicaba, v. 8, n. 19, p. 37-44, 2006.

LORENZI H.F. e MATOS F.J.A.. Plantas Medicinais do Brasil, nativas e exóticas. 1 ed. p. 544, São Paulo: Instituto Plantarum. 2002.

MACIEL, M. A. M. et al. Medicinal plants: The need for multidisciplinary scientific studies. Quimica Nova, v. 25, n. 3, p. 429-438, 2002.

MENEZES, S. M. S.; PINTO, D. M.; CORDEIRO, L. N.. Atividades biológicas in vitro e in vivo de Punica granatum L. (romã). Revista Brasileira de Medicina. v. 65, n. 11, p. 388-391, 2008.

NASCIMENTO, G.F. et al. Antibacterial activity of plant extracts and phytochemicals on antibiotic-resistant bacteria. Revista Brasileira de Microbiologia v. 31, p. 48-53, 2000.

NEGI, P. S. JAYAPRAKASHA, G. K. Antioxidant and antibacterial activities of Punica granatum peel extracts. J Food Sci. 200368.

OLIVEIRA, L.P. et al. Atividade citotóxica e antiangiogênica de Punica granatum L.,

Punicaceae. Revista Brasileira de Farmacognosia, v. 20, n. 2, p. 201-207, Abr./Mai. 2010.

OSTROSKY, E. et al. Métodos para avaliação da atividade antimicrobiana e determinação da concentração mínima inibitória (CMI) de plantas medicinais. Revista Brasileira de Farmacognosia. v.18, n. 2, p. 301-307, Abr./Jun. 2008.

PEREIRA, J. V. et al. Efeito antibacteriano e antiaderente in vitro do extrato da Punica granatum Linn. sobre microrganismos do biofilme dental. Revista Brasileira de Farmacognosia, v. 16, n.1, p. 301-307, João Pessoa. Jan./Mar. 2006.

PERON, A. P. et al. Avaliação do Potencial Citotóxico dos Chás de Caellia sinensis L. e Cassia angustifolia Vahl em sistema teste vegetal. Arq. Ciênc. Saúde Unipar, Umuarama, v. 12, n. 1, p. 51-54, jan./abr. 2008.

PRASHANTH, D., ASHA, M.K., AMIT, A. Antibacterial activity of Punica granatum. Fitoterapia 2001 72:171-173

SAMUELSEN, A.B. The traditional uses, chemical constituents and biological activities of Plantago major L. A review. J. Ethnopharmacol. v. 71, n. 1-2, p. 1-21, Jul. 2000.

TAUFNER CF, FERRAÇO EB \& RIBEIRO LF (2006). Uso de plantas medicinais como alternativa fitoterápica nas unidades de saúde pública de Santa Teresa e Marilândia, ES. Natureza on line. v. 4, n. 1, p. 30-39, 2006.

VEIGA JR, V. F.; PINTO A.C.; MACIEL, M. A. M. Medicinal plants; safe cure? Química Nova, v. 28, n. 3, p. 519528, 2005.

ZAGO, J. A. A.. Sinergismo entre óleos essenciais e drogas antimicrobianas sobre linhagens de Staphylococcus aureus e Escherichia coli. Revista Brasileira de Farmacognosia, v. 19, n. 4, p. 828-823, Out./Dez. 2009. 